\title{
Depression and Anxiety: A Snapshot of the Situation in Pakistan
}

\author{
Zafar Iqbal $^{1}$, Ghulam Murtaza ${ }^{2}$, Shahid Bashir ${ }^{3, *}$ \\ ${ }^{1}$ Drug Testing Laboratory, Azad Jammu \& Kashmir, Pakistan \\ ${ }^{2}$ Department of Neurology, Faculty of Medicine, King Saud University, Saudi Arabia \\ ${ }^{3}$ Department of Physiology, Faculty of Medicine, King Saud University, Saudi Arabia
}

Copyright $\mathrm{O} 2016$ by authors, all rights reserved. Authors agree that this article remains permanently open access under the terms of the Creative Commons Attribution License 4.0 International License

\begin{abstract}
Background: Depression is a great cause of morbidity around the world. Not one person seems to escape the hollow dread that the disease can bring forth. Aims: Although living in a large extended family which serves as a social support is common in Pakistan, why we still suffer from anxiety and depression just as often if not more than those in other countries? Method: We checked studies conducted in different localities of Pakistan over the past 10 years to find prevalence values of anxiety and depression.

Results: The values of anxiety and depression ranging from $22 \%$ to as high as $60 \%$ in a given population high rates necessitate the spread of awareness and action against mental health issues. Conclusions: It is a mental disorder that can create numerous concerns in many aspects of the sufferer's life. The disabling moods of depression can damage a person's marriage, family relationships, friendships, job performance, and health. The longer depression persists, the more widespread the damage. Major depression can result in people shutting themselves off from the support of friends and family or striking out violently by verbally and physically attacking others.
\end{abstract}

Keywords Depression, Anxiety, Pakistan

\section{Introduction}

Depression is a great cause of morbidity around the world. Not one person seems to escape the hollow dread that the disease can bring forth. With an estimated population of 170 million people, Pakistan is the sixth most populous country in the world and by 2050 it is projected to rank fourth [1] (UN report 1999). Depression has been predicted to rise to second rank in both genders by 2020 [2]. It is estimated that $10-44 \%$ of the people living in developing countries are affected by depression disorders and almost 50.8 million are undergoing depression [3]. Pakistan's rapidly increasing population and the pivotal role it plays in current world events highlight a great need to develop an evidence base for guiding future policy and implementing new strategies that address depression. Although living in a large extended family which serves as a social support is common in Pakistan, studies showed that we still suffer from anxiety and depression just as often if not more than those in other countries $[4,5,6,7]$.

Dogar et al. reported prevalence of depressive and anxiety disorders in hospitalized cardiac patients in Pakistan [8]. Rates of depression and anxiety were high among females as compared to that of males [8]. In addition, diabetic patients also face depression and anxiety problems. In a study of 133 diabetic patients, $38 \%$ were found depressed, and depression rate was significantly higher among female patients [9]. Begum et al., 2014 compared depression and anxiety rates between fertile and infertile women of the same age group and found significantly higher rates of depression and anxiety in infertile women compared to that of fertile women. Depression and anxiety rates among fertile women were 21.85 and 24.45 , respectively and among infertile women were 32.01 and 36.20, respectively [10].

Currently, Pakistan is fighting against terrorism as frontline state since 2001. Terrorism not only causes loss of life but also affects behavioral and psychological responses. Physical and mental trauma is included in these psychobiological effects [6]. Psychiatric morbidity among medical students was also found to be associated with terrorism. Impact of terrorism on their social and mental health was $178(17.2 \%)$ and 818 (79\%), respectively [7].

Various studies conducted in different localities of Pakistan over the past 10 years give prevalence values of anxiety and depression ranging from $22 \%$ to as high as $60 \%$ in a given population $[1,2,5,11-21]$. Such high rates necessitate the spread of awareness and action against mental health issues.

\section{Socioeconomic Status and Mental Health}

Local studies have brought to light a great number of associated factors resulting in anxiety and depression. Some of the major associations are being female (and often 
housewives) $[12,14,15,16]$ having social and familial issues [9-16], suffering from illnesses and chronic diseases [11-14], possessing a low level of education [11-16] and dealing with financial issues $[18,19]$. Supportive family and friends may be helpful in averting these mental stressors [23]. Low socioeconomic status (SES) is generally associated with high psychiatric morbidity, disability, and poor access to health care $[24,25]$. Across the world, less educated groups typically show a higher prevalence of psychiatric morbidity [26] as they do in Pakistan [11-16]. Stress and weaker social support combined with a lack of coping mechanisms are psychiatric risk factors that may pre-dispose lower SES groups to depression and anxiety [27]. Two studies show that families following more of a nuclear system rather than an extended joint family system had a greater prevalence of depression [11, 18]. The outcomes of higher mental morbidity are found unequally distributed with lower SES groups facing more disabilities [25] and a poorer prognosis [26]. In low-income countries, lower SES groups tend to face obstacles to accessing health care [27, 28]. In Pakistan some studies indicate that there is a general apprehension of seeking mental health care and psychiatric treatment $[29,30,31]$. This could be due to social stigma, a lack of awareness or a desire to be treated by faith healers amongst other potential reasons [16].

Socio-economic status explains much about why people in our society experience so much depression. When people do not have enough to eat or cannot provide for their families, they tend to suffer from depression. In a country where making ends meet is often difficult the prevalence of depression is not all that surprising. Another study has shown that patients from low-income backgrounds are less likely to respond to antidepressant treatment indicating SES plays a role in responsiveness to antidepressants [32]. Furthermore, a string of natural disasters beginning with the catastrophic earthquake in 2005 and massive flooding in 2010 have resulted in conditions of despair which further contribute to depression [18]. Pakistan also has some of the highest infant and maternal mortality rates in the world [33], which has an impact on mental health [12].

\section{Globalization and Mental Health}

In developing countries, lower income classes disproportionately suffer the greatest from depression and receive less mental health care compared to the country's more privileged populations. This has been described as the "inverse care law." (Hart 1971) Although brain health care in Pakistan has improved in several ways due to globalization, mental health care for the poor may not be improving on the whole. There are three main reasons for this as described by Fregni: 1- inadequate psychiatric training that is unsuitable for local conditions; 2- an increase in global health care expenditures that takes resources from mental health care; and 3- a lack of clinical research in brain health care [33].

From the perspective of mental health, Patel puts forth an interesting concern in India that psychiatrists there are being trained to treat cases typical of those found in textbooks and journals from western countries [34]. A randomized control trial showed that even minimally trained counselors provided benefit to anxious and depressed women from their community [35]. In Pakistan, efforts have been made to ensure training meets the local demands, but the extent to which this is done is unknown.

Globally, health care costs have been rising for several years. In the United States, health care expenditures nearly doubled between 1990 and 2003, from $\$ 696$ billion to $\$ 1.7$ trillion [36]. This increase was less pronounced in Pakistan, where health care expenditures amount to less than $1 \%$ of the GNP [37, 38] Unfortunately, being confronted with increasing health care costs on a limited budget, politicians make cuts in important areas such as mental health care ( $0.4 \%$ of the total budget) [38] which disproportionately affects the poor. Any cost incurred for treatment is paid directly by the patient as there are few insurance facilities, little coverage through companies and the government generally does not take part in the burden [34].

Treatment and Rehabilitation: In primary care, the range of interventions offered may extend from watchful waiting through guided self-management, brief psychological or behavioral interventions, pharmacological management, and, if needed, referral to more specialized services or hospital admission. Pharmacological agents are one of several treatment modalities used for depression. One of the most frequently utilized classes of antidepressant medications are the selective serotonin-reuptake inhibitors (SSRIs). It is generally accepted that a $50 \%$ decrease in symptom severity constitutes a response to SSRI medication. Remission from depression is defined as being free or nearly free of symptoms for the current episode. A portion of patients who have experienced an inadequate response from a clinical perspective may also go on to have their depression defined as treatment resistant if it also fails to respond to subsequent treatment strategies. All this would suggest the difficulty of defining and capturing subjects who have had treatment failure and related subgroups. It may also reflect heterogeneity across studies evaluating the efficacy of selective serotonin-reuptake inhibitors within this patient population.

\section{Lack of Therapeutic Interventions for the Improvement of Depression in Pakistan}

Psychiatric comorbidities present in patients with depression and anxiety are one of the major causes of treatment failure. Considering the complexities of the illness of depression, managing these comorbidities via any intervention, along with depression specific therapies, is very complicated and at times ineffective. Brain stimulation interventions could provide efficient answers to this problem in the field of depression medicine. 
Depression and Transcranial Direct Current Stimulation: tDCS is a simply non-invasive brain stimulation method.it is direct electrical current and is applied using 2 scalp surface electrodes that are covered by sponges and soaked in saline. Findings from preclinical studies suggest that tDCS may cause polarity-dependent alterations in cortical excitability and activity [39]. Anodal stimulation increases cortical excitability and cathodal stimulation decreases cortical excitability. The changes in cortical excitability are probably through respective depolarization and hyper- polarization of neurons. It shows that this effect can be attributed to a subthreshold modulation of resting membrane potential, and it can persist even after stimulation stops. In consequence of its ability to alter cortical activity, Researchers started investigating the uses of tDCS as a treatment for depression in the 1960s. On the clinical effects of tDCS on tinnitus [40], major depressive disorder [41, 42] and pain [43, 44-50], and smoking addiction [46]. Interesting in tDCS as a treatment for depression has led to several researches that examined optimal treatment efficacy of tDCS.

\section{Towards a Mental Health Agenda}

As in many other developing countries, Pakistan lacks a clear research agenda when it comes to mental health. Progress has been taking speed with an increase in the number of studies on the subject being published. However a lot more effort is required and much remains to be done. Numerous large scale trials have been carried out in Pakistan, however few of these focus solely on depression. One trial involved the development of a culturally sensitive Cognitive Behavioral Therapy that proved effective in reducing symptoms of depression [51]. Without a strong information base bolstered by a research agenda to investigate mental health treatments and interventions, developing local solutions to Pakistan's mental health problems will be very difficult. The beneficial effects of Pakistan's 'National Mental Health Policy' and 'Mental Health Act' in 2001, although steps in the right direction, have yet to reach full fruition.

In comparison to other developing countries, Pakistan has the highest depression rate accounting for abundant reasons like economic issues, insecurity, political uncertainty, unemployment, stressful working conditions, gender discrimination and disruption of the social settings $[7,8]$.

The prevalence of depression continues to rise due to no appropriate governmental policy on mental illnesses [8]. The situation is further aggravated by the social taboo on seeing a psychiatrist with majority people opting for faith healers and alternative medications that complicate the illness [10]. The free and rapid flow of information resulting from globalization has allowed for significant advances in global health. The widespread use of vaccines to combat easily preventable diseases of the developing world testifies to this fact. At the same time, however, inequalities in developing countries like Pakistan have been exacerbated by the ever-increasing rate at which new technology reaches those with resources leaving the poor struggling behind. A stronger evidence base for new policies and a structured approach to addressing disparities in mental health are critical for improving the lives of all Pakistanis.

\section{Acknowledgements}

This work was financially supported by Deanship of Scientific Research at King Saud University for funding this work through research group no RGP-VPP-216.

\section{REFERENCES}

[1] Katz SJ, Kessler RC, Frank RG, et al. Mental health care use, morbidity, and socioeconomic status in the United States and Ontario. Inquiry 1997;34:38-49

[2] Desjarlais R. World Health Report. Geneva: World Health Organization; 2001.

[3] W.H.O. Mental Health Report: New Understanding, New Hope. World Health Report. Geneva, Switzerland: 2001.

[4] Husain N, Creed F, Tomenson B. Depression and social stress in Pakistan. Psychol Med. Mar 2000; 30(2):395-402.

[5] Husain N, Chaudhry N, Tomenson B, Jackson J, Gater R, Creed F. Depressive disorder and social stress in Pakistan compared to people of Pakistani origin in the UK. Soc Psychiatry Psychiatr Epidemiol. Nov 282010.

[6] Asad N, Karmaliani R, Sullaiman N, et al. Prevalence of suicidal thoughts and attempts among pregnant Pakistani women. Acta Obstet Gynecol Scand. Dec 2010; 89 (12):1545-1551.

[7] Luni FK, Ansari B, Jawad A, Dawson A, Baig SM. Prevalence of depression and anxiety in a village in Sindh. J Ayub Med Coll Abbottabad. Apr-Jun 2009; 21(2):68-72.

[8] Ganatra HA, Zafar SN, Qidwai W, Rozi S. Prevalence and predictors of depression among an elderly population of Pakistan. Aging Ment Health. May 2008; 12(3):349-356.

[9] Khan H, Kalia S, Itrat A, et al. Prevalence and demographics of anxiety disorders: a snapshot from a community health centre in Pakistan. Ann Gen Psychiatry. 2007; 6:30.

[10] Taqui AM, Itrat A, Qidwai W, Qadri Z. Depression in the elderly: does family system play a role? A cross-sectional study. BMC Psychiatry. 2007; 7:57.

[11] Muhammad Gadit AA, Mugford G. Prevalence of depression among households in three capital cities of Pakistan: need to revise the mental health policy. PLoS One. 2007; 2(2): e209.

[12] Husain N, Chaudhry IB, Afridi MA, Tomenson B, Creed F. Life stress and depression in a tribal area of Pakistan. Br J Psychiatry. Jan 2007; 190:36-41.

[13] Saeed K, Gater R, Hussain A, Mubbashar M. The prevalence, classification and treatment of mental disorders among attenders of native faith healers in rural Pakistan. Soc 
Psychiatry Psychiatr Epidemiol. Oct 2000; 35(10):480-485.

[14] Mumford DB, Saeed K, Ahmad I, Latif S, Mubbashar MH. Stress and psychiatric disorder in rural Punjab. A community survey. Br J Psychiatry. May 1997; 170: 473-478.

[15] Population Division, Department of Economic and Social Affairs, United Nations Secretariat. U.N. The world at six billion (ESA/P/WP.154) Part 2-Table 5-8. New York: UN, 1999: 12-22.

[16] Imam SZ, Hashmi SH, Islam MG, et al. Liaison psychiatry and depression in medical inpatients. J Pak Med Assoc. Mar 2007; 57(3):159-162.

[17] Ali FA, Israr SM, Ali BS, Janjua NZ. Association of various reproductive rights, domestic violence and marital rape with depression among Pakistani women. BMC Psychiatry. 2009; 9:77.

[18] Syed EU, Khan MM. Pattern of deliberate self-harm in young people in Karachi, Pakistan. Crisis. 2008; 29(3):159-163.

[19] Turner RJ, Lloyd DA. The stress process and the social distribution of depression. J Health Soc Behav 1999; 40:374 404.

[20] Bebbington P, Brugha T, Meltzer H, et al. Psychiatric disorder and dysfunction in the UK National Survey of Psychiatric Morbidity. Soc Psychiatry Psychiatr Epidemiol 2000; 35:191-7.

[21] Lorant V. et al. Socioeconomic Inequalities in Depression: A Meta-Analysis. Am J Epidemiology 2003; 157:98-112.

[22] Andrade L, Caraveo-Anduaga JJ, Berglund P, et al. Cross-national comparisons of the prevalences and correlates of mental disorders. Bull World Health Organ 2000;78:41326.

[23] Alegria M, Bijl RV, Lin E, et al. Income differences in persons seeking outpatient treatment for mental disorders: a comparison of the United States with Ontario and the Netherlands. Arch Gen Psychiatry 2000; 57:383-91.

[24] Patel MJ, Shahid M, Riaz M, et al. Drug overdose: a wake up call! Experience at a tertiary care centre in Karachi, Pakistan. J Pak Med Assoc. Jun 2008; 58(6):298-301.

[25] Gadit AA. Out-of-Pocket expenditure for depression among patients attending private community psychiatric clinics in Pakistan. J Ment Health Policy Econ. Mar 2004;7(1):23-28.

[26] Gadit AA. Economic burden of depression in Pakistan. J Pak Med Assoc. Feb 2004; 54(2):43-44.

[27] Dohrenwend BP, Dohrenwend BS. Social status and psychological disorder: a causal inquiry. New York, NY: John Wiley and Sons, Inc, 1969.

[28] Cohen A., et al., Social inequalities in response to antidepressant treatment in older adults. Arch Gen Psychiatry, 2006.

[29] Hussain A, L Weisaeth, and T Heir. Psychiatric disorders and functional impairment among disaster victims after exposure to a natural disaster: A population based study. J Affect Disord. (2008) [E-pub ahead of print]

[30] Bhutta $Z$ et al. Countdown to 2015 decade report: taking stock of maternal, newborn, and child survival. The Lancet. 2010; 375: 2032-2044.
[31] Hart JT. The inverse care law. Lancet. 1971;1(7696):405-412.

[32] Fregni F. Implications of globalization for mental health care in Brazil. Revista: Harvard Review of Latin America. 2007, Available at: http://www.drclas.harvard .edu/ revista/articles/view/940. Accessed October 13, 2010.

[33] Patel V. The need for treatment evidence for common mental disorders in developing countries. Psychol Med 2000; 30: 743-746.

[34] Ali BS, Rahbar MH, Naeem S, Gul A, Mubeen S, Iqbal A. The effectiveness of counseling on anxiety and depression by minimally trained counselors: a randomized controlled trial. Am J Psychother. 2003; 57(3):324-336.

[35] Karim S, Saeed K, Rana MH, Mubbashar MH, Jenkins R. Pakistan mental health country profile. Int Rev Psychiatry. Feb-May 2004; 16(1-2):83-92.

[36] Akram M, Khan FJ. Health care services and government spending in Pakistan. In: Pakistan Institute of Development Economics Working Papers. Available at: www.pide.org.pk. Accessed October 13, 2010

[37] Naeem F, Waheed W, Gobbi M, Ayub M, Kingdon D. Preliminary evaluation of culturally sensitive CBT for depression in Pakistan: findings from Developing Culturally-sensitive CBT Project (DCCP). Behav Cogn Psychother. Mar 2011; 39(2):165-173.

[38] Yehuda R, Hyman SE. The impact of terrorism on brain and behavior: what we know and what we need to know Neuropsychopharmacology 2005; 30: 1773-80.

[39] Nasim S, Khan M, Aziz S. Impact of terrorism on health and Hospital Anxiety Depression Scale screening in medical students, Karachi, Pakistan. J Pak Med Assoc. 2014 Mar; 64(3):275-80.

[40] Bouchoucha M1, Hejnar M, Devroede G, Babba T, Bon C, Benamouzig R. Anxiety and depression as markers of multiplicity of sites of functional gastrointestinal disorders: a gender issue? Clin Res Hepatol Gastroenterol. 2013 Sep; 37(4):422-30.

[41] Dogar IA1, Khawaja IS, Azeem MW, Awan H, Ayub A, Iqbal $\mathrm{J}$, Thuras P. Prevalence and risk factors for depression and anxiety in hospitalized cardiac patients in pakistan. Psychiatry (Edgmont). 2008 Feb; 5(2):38-41.

[42] Arshad AR1, Alvi KY1. Frequency of depression in type 2 diabetes mellitus and an analysis of predictive factors. J Pak Med Assoc. 2016 Apr; 66(4):425-9.

[43] Begum BN, Hasan S. Psychological problems among women with infertility problem: a comparative study. J Pak Med Assoc. 2014 Nov; 64(11):1287-91.

[44] Khan MN, Chiumento A, Dherani M, Bristow K, Sikander S, Rahman A. Psychological distress and its associations with past events in pregnant women affected by armed conflict in Swat, Pakistan: a cross sectional study. Confl Health. 2015 Dec 10; 9:37. doi: 10.1186/s13031-015-0063-4. eCollection 2015.

[45] Altaf A, Khan M, Shah SR, Fatima K, Tunio SA, Hussain M, Khan MA, Shaikh MA, Arshad MH. Sociodemographic Pattern of Depression in Urban Settlement of Karachi, Pakistan. J Clin Diagn Res. 2015 Jun;9(6) 
[46] De Ridder D., Vanneste S. (2012). EEG driven tDCS versus bifrontal tDCS for Tinnitus. Front. Psychiatry 3:84.10.3389/fpsyt.2012.00084

[47] Blumberger D. M., Tran L. C., Fitzgerald P. B., Hoy K. E., Daskalakis Z. J. (2012). A randomized double-blind sham-controlled study of transcranial direct current stimulation for treatment-resistant major depression. Front. Psychiatry 3:74.10.3389/fpsyt.2012.00074

[48] Knotkova H., Rosedale M., Strauss S. M., Horne J., Soto E., Cruciani R. A., et al. (2012). Using transcranial direct current stimulation to treat depression in HIV-infected persons: the outcomes of a feasibility study. Front. Psychiatry 3:59.10.3389/fpsyt.2012.00059.
[49] DosSantos M. F., Love T. M., Martikainen I. K., Nascimento T. D., Fregni F., Cummiford C., et al. (2012). Immediate effects of tDCS on the mu-opioid system of a chronic pain patient. Front. Psychiatry 3:93.10.3389/fpsyt.2012.00093 [PMC free article] [PubMed] [Cross Ref]

[50] Fecteau S., Boggio P., Fregni F., Pascual-Leone A. (2012). Modulation of untruthful responses with noninvasive brain stimulation. Front. Psychiatry 3:97.10.3389/fpsyt.2012.0009 7 [PMC free article] [PubMed] [Cross Ref]

[51] Fraser P. E., Rosen A. C. (2012). Transcranial direct current stimulation and behavioral models of smoking addiction. Front. Psychiatry 3:79.10.3389/fpsyt.2012.00079 